\title{
Diálogos Possíveis: Entrevista com Natalia Borges Polesso
}

\author{
PAULO DUTRA \\ Stephen F. Austin State University
}

Na edição de 2018 da Primavera Literária, em Evanston, IL, numa das várias mesas a que assisti, houve dois momentos que chamaram minha atenção de maneira intrigante para uma das pessoas que participavam do painel. Em dado momento, após uma pergunta dirigida à mesa, percebi que nossas cabeças balançaram ao mesmo tempo em sinal de negativa. Em outra ocasião, um gesto de esconder seus olhos com as duas mãos refletiram minha reação, que só se deu no plano mental, a outro comentário. Essa espécie de sintonia relampejante fomentou o interesse em estender o que havia sido uma rápida troca de palavras - no corredor adjacente à sala em que ocorreu o debate-a uma entrevista com a, então para mim desconhecida, vencedora de dois Prêmios Jabuti e de dois Prêmios Açorianos, Natalia Borges Polesso. ${ }^{1}$ Já que a distância se apresentou como uma barreira, a autora gentilmente concordou em conceder esta entrevista por meio de conversas em redes sociais e correspondência por emails.

Professora e escritora, doutora em Teoria da Literatura, já em sua estreia na literatura, em 2013, com Recortes para álbuns de fotografia sem gente, recebeu o mais importante prêmio do Rio Grande do Sul, estado onde nasceu, realizou seus estudos de graduação e pós-graduação e para onde regressou após residir temporariamente na Europa por conta da realização de um período de doutoradosanduíche. Após a publicação de um livro de poesia em 2015 e do aclamado, internacionalizado em traduções e quatro vezes premiado Amora (2016), Natalia

${ }^{1}$ Com Amora, Natalia Borges Polesso ganhou o prêmio da Associação Gaúcha de Escritores (AGES), o Açorianos e o Jabuti, este último em duas categorias. Além disso, neste ano de 2018, Amora foi aprovado no Plano Nacional do Livro Didático (PNLD) e um excerto do conto "Vó, a senhora é lésbica?" foi selecionado para fazer parte de uma das questões do Exame Nacional do Ensino Médio (ENEM). 
Borges Polesso foi recentemente incluída na lista Bogotá39 de 2017, o que significa que seu nome está entre os dos/das escritores mais promissores da América Latina com idade abaixo dos 40 anos.

PD: Você já deveria dispensar apresentações, porém, a "anedota" que você compartilhou sobre a ida ao banco é um indicador da posição de uma autora como você no Brasil. Você poderia comentar sobre a sua visita ao banco e o que ela implica?

NBP: Não posso deixar de rir ao me lembrar dessa história, não um riso de graça, de condescendência, um riso sarcástico, é claro. Ir ao banco para pedir um aumento de limite no cartão de crédito, no mesmo dia que você está na capa do jornal da cidade, por conta de um prêmio literário, parece algo meio insólito, mas que está a seu favor. Insólito porque, se você ganhou um prêmio, teoricamente deveria estar já encaminhada na profissão, reconhecida, valorizada. Pena que não é bem assim que as coisas acontecem. Ao menos não no Brasil. Já adianto o final da história: sim, eu ganhei mais limite. E foi justamente por ser escritora. Não, não foi admiração. Foi um pouco de pena e uma correlação imediata que a gerente fez com o filho dela: "meu filho quer ser escritor, mas ele é tão inteligente, pode ser arquiteto, médico...", me disse sem nenhum pudor, enquanto me olhava com as sobrancelhas caídas, pensando no que poderia fazer para me ajudar e, provavelmente, contribuindo para um bom karma, na certeza que, se seu filho fosse mesmo escritor um dia, alguém também iria ajudá-lo. Assim sou escritora no Brasil. Não posso apenas pensar em escrever livros, antes preciso pensar em como me manter para escrevê-los. Hoje, posso dizer que trabalho em três empregos que amo muito: o de pós-doutoranda-pesquisadora-da-literatura, que é o que paga minhas contas; o de escritora, que me mantém respirando e me dá motivos para seguir e às vezes paga legal, depois de mais reconhecimentos; e o de cronista semanal que, confesso, mais me estressa do que me agrada. Ah, também ministro cursos e oficinas não acadêmicas, o que é muito bacana e me dá a oportunidade de conhecer muitas pessoas que estão aí às voltas com seus escritos. Hoje estou bem. Já fiz muitos outros serviços não vinculados à literatura, já trabalhei como secretária, faxineira, estagiária-faz-tudo, balconista numa locadora de livros (!), garçonete, enfim, a vida é isso. Trabalhar não é tudo, mas a gente faz umas coisas para poder fazer outras. Agora, sobre o "dispensar 
apresentações", não sei disso não. Acho que apresentar é sempre dar margem a uma perspectiva interessante de nós.

PD: Como dito acima, balançamos a cabeça negativamente no mesmo instante. Foi naquele momento em que uma pergunta que não se costuma fazer a homens foi direcionada a uma mesa composta por mulheres. Você pode por favor comentar essa questão das "perguntas inadequadas"?

NBP: A pergunta era como conciliar a vida doméstica/familiar e a carreira de escritora/pesquisadora, né? Nem sei o que dizer. A Rebecca Solnit tem um livro inteiro de ensaios dedicado a perguntas desnecessárias ou que às vezes não merecem uma resposta. ${ }^{2}$ Eu respondi, porque, sempre que posso, faço questão de dizer que sou casada com uma mulher e que nosso lar difere de um lar normativo. Mas também fiz questão de sinalizar o quão inapropriada era aquela pergunta e se ela seria feita para uma mesa composta de homens. Acho que não. Por que isso em 2018? Aliás, a Virgínia Woolf já falava em matar o anjo doméstico lá em 1929. Com tantas opções mais interessantes para perguntar sobre nosso trabalho intelectual, sobre nossas produções, nossas estéticas, nossos posicionamentos políticos com relação à arte; poderiam perguntar sobre nossas personagens, sobre como criamos, como nos organizamos para manter nossa vida criativa, enfim, poderia seguir por um bom tempo aqui, aventando possibilidades. Mas vou contar sobre outra pergunta inadequada, a qual sempre me lembro. Foi numa revista de literatura, logo que o Amora ganhou certa mídia: você quer escancarar o universo lésbico? Primeiramente, até aquela pergunta, eu pensava que habitássemos todos o mesmo universo, e, se o perguntador não enxergava isso, o problema não era meu. Eu não estava escancarando nada. Estava apenas contando histórias sobre personagens cujo modo de ocupar o mundo leva a identidade lésbica como fator principal. Ademais, se existisse um universo exclusivamente lésbico, é óbvio que eu estaria lá e não neste aqui compartilhado. Mas, é curioso, acho que ninguém nunca perguntou ao Philip Roth se ele queria escancarar o universo heterossexual.

\footnotetext{
${ }^{2}$ Rebecca Solnit, The Mother of All Questions: Further Reports from the Feminist Revolutions, Haymarket, 2017.
} 
PD: O luxuoso exemplar de Amora que chegou a minha estante é claramente o resultado de um tratamento editorial refinado. Se não me falha a memória, o livro está em sua quarta reimpressão/edição. Você pode comentar sobre esse percurso entre a primeira edição e a atual?

NBP: Posso comentar, sim, mas acho que não em termos de edição. O trabalho que a Não Editora fez (e tem feito) pelo livro é incrível. O projeto gráfico é do Guilherme Smee e a capa lindíssima é do Samir Machado de Machado, cujo trabalho admiro muito. Acho que o que posso comentar melhor é o retorno que tive de leitores e da crítica. Acho que, antes mesmo de ganhar os prêmios que o Amora ganhou, a primeira edição já estava quase esgotada. Isso era um sinal de que as pessoas estavam lendo. Além disso, eu recebi muitas mensagens, e-mails, contatos em geral de pessoas contando sua experiência de leitura e compartilhando coisas profundas e pessoais de suas vidas comigo. Eu ainda recebo, na verdade. São mensagens longas cheias de carinho, e isso é uma das coisas que mais me dá alegria sobre o livro, esse compartilhamento, essa noção de que estamos ligados e ligadas por algum tipo de sentimento ou vivência. Os caminhos do Amora têm sido muito bonitos e eu fico muitíssimo feliz com isso. Depois do Açorianos e dos Jabutis, acho que a coisa aumentou consideravelmente, passei a viajar mais, dentro e fora do Brasil, passei a conhecer mais leitores e leitoras, e até mesmo a minha construção do que seria essa literatura lésbica teve que ser repensada. Meu projeto atual de pós-doc (Geografias homoafetivas: literatura e gênero) é fruto dessa caminhada.

PD: Há algo que notei sobre a linguagem em Amora que me pareceu ser uma tendência na literatura contemporânea. Refiro-me a certos empregos (como o do pretérito mais-que-perfeito em sua forma simples) que destoam completamente da linguagem falada cotidiana. Como você descreveria sua "linguagem literária" em relação ao emprego ou distanciamento da linguagem "real" que se usa no cotidiano?

NBP: Acho que meu primeiro livro é muito mais assim, nessa linguagem que eu chamaria de mais poética. No Amora, tentei não fazê-lo, a menos que as personagens quisessem assim se expressar (como é o caso da Dramaturga Hermética, que tem uma linguagem mais rebuscadamente patética). Acho que o 
Amora se aproxima bastante da linguagem cotidiana. Será que estou enganada? (risos). Não sei se é possível hoje, no meio do turbilhão da profícua produção literária brasileira, ver alguma tendência. Eu tenho lido tanto prosa quanto poesia e vejo uma diversificação imensa de temas, estilos, estéticas...

PD: Talvez meu distanciamento da produção literária brasileira contemporânea - que se deve tanto à minha formação quanto às exigências específicas da minha profissão (professor de espanhol) - seja responsável por essa impressão. Creio que me referia mais aos narradores e às narradoras que a personagens quando falei sobre "tendências" a empregar certas formas expressivas. E volto a tocar na mesma tecla: por que você chamaria então tal ou qual linguagem de "mais poética"? Quais são os critérios seguidos, se é que há algum definido de fato?

NBP: Se eu entendi bem, e aqui junto as duas perguntas anteriores, você quer que eu tente falar um pouco da minha "linguagem literária." Bem, eu sempre recorro ao Barthes nessas horas, que afirmava que não podemos controlar o estilo. Decerto é isso. Essa coisa que precede a escrita, que está na linguagem e no jeito que nos relacionamos com ela e no mundo. Se observo meus livros todos, talvez eu encontre um único texto imenso e contíguo, com recorrência de metáforas, de esquemas, mesmo de ordem das palavras, porque o ofício da escrita é este: tentar não escrever sempre a mesma história. Meu primeiro livro tem contos curtíssimos, poderia até classificá-los como minicontos ou flash fiction. São peças em que a história pouco importa. Naqueles textos me tocava mais o encontro das palavras, a tentativa de surpreender com imagens. Por isso digo que ele pende levemente para o lado da poesia. Meu segundo livro é de poemas e, ao fim, tenho doze pequenos textos de prosa poética. Ou poemas em prosa. A classificação é o que menos importa. Com Amora, me preocupei em criar personagens, narradoras, e sim me preocupei em contar histórias de fato, para tanto, busquei uma linguagem mais simples. Talvez uma busca lexical mais simples, por vezes até coloquial, já que precisava dar alguma característica específica para personagens. Houve quem dissesse até que meu livro soava "do interior." Disso não sei. Contudo, há coisas que não consigo evitar. Isso, segundo Barthes, é o tal estilo. 
PD: Mudando um pouquinho de assunto, o recrudescimento de posturas e discursos conservadores pode ser visto a olho nu, como se costuma dizer. De que maneira isso te afeta?

NBP: Isso me afeta mais diretamente quando assumo a profissão de cronista. Sou uma mulher lésbica de esquerda, escrevendo para um jornal que não tem exatamente uma postura tão paralela assim à minha. Bem, eu deixei de ler comentários, desfiz meu cadastro do portal além de não permitir marcações no meu facebook, porque o tempo que eu gastava lendo insultos era absurdo. Isso pode mesmo acabar com a saúde de uma pessoa. Preferi não ver. Às vezes compartilho alguma postagem. Isso me incomoda mesmo no campo da literatura porque, infelizmente, a leitura não é tão ampla e imediata como a do jornal. Há um público, em geral especializado. A luta neste campo é outra. É pela validação. E é também sobre o que contei em uma das perguntas anteriores. Amora não é um livro com temática LGBT, é um livro que usa o recurso estético do ponto de vista para compor personagens que têm modos não normativos de estar no mundo, especialmente no que diz respeito ao afeto, às relações, à ocupação dos lugares. Essas narrativas, e não estou sozinha, a produção de autoras lésbicas tem se destacado cada vez mais no cenário brasileiro e estrangeiro, tem o poder de criar novas estéticas, novas vozes, novos modos de ocupar o campo da literatura.

PD: Gostei muito dessa explicação sobre Amora não ser um livro com temática LGBT, porque foi exatamente a impressão que tive ao ler os contos. Acho que um dos inumeráveis méritos do livro e da sua construção narrativa é exatamente isso, e o fato de que, como você ressaltou, essas narrativas terem esse poder de gerar novas estéticas, vozes e, principalmente, modos de ocupar (uso o verbo como intransitivo de maneira proposital). Você pode dar um exemplo de um modo novo de ocupar o campo da literatura?

NBP: Bem, posso começar falando sobre a pesquisa de Regina Dalcastagnè, professora e pesquisadora na UnB. $O$ grupo de pesquisa em literatura contemporânea brasileira estabeleceu o perfil do escritor brasileiro e das personagens da literatura. $\mathrm{O}$ corte foi feito com romances de quatro editoras consideradas grandes. É claro que o resultado não foi muito animador. Os autores são em maioria homens brancos heterossexuais. As mulheres vêm publicando 
mais, sem dúvidas, mas os números ainda não são equânimes. Quanto às personagens, são em maioria homens brancos heterossexuais. Há menos mulheres do que homens, há poucos negros, pouquíssimos indígenas e quando se trata do corte LGBTQ+ também somos poucas personagens. (A CULT fez uns gráficos bem bacanas). ${ }^{3}$ Isso não é gratuito. O que está por trás dessas publicações são mecanismos de legitimação do próprio campo literário. Se as grandes editoras publicam isso em maior número, não significa exatamente que não há outra produção, significa que esta produção não está circulando, está oculta, silenciada, marginalizada. Lembro-me de na adolescência, quando me deparava com algum personagem gay (mais facilmente encontrado, porque as lésbicas eram todas "estavam numa fase" ou "passando por dúvidas"), lia e relia com muita atenção aquelas passagens que pra mim eram ouro, que me diziam algo pessoal, que me fizeram querer buscar mais literatura. Mas só fui encontrar Cassandra Rios, Angélica Freitas, Marília Floor Kosby, Cidinha da Silva, Andrea Salgado, Diedra Roiz e as personagens de Conceição Evaristo muito recentemente. Acho que essa pesquisa da Regina nos ajudou a cavoucar mais coisas. Desde 2013, tenho lido mais mulheres, mais LGBTs, mais autoria negra, e é claro que minha cartografia pessoal da literatura mudou imensamente. Passei a conhecer outras livrarias, outras editoras, outros grupos de estudo, de leitura, assim como outras personagens se apresentaram para mim com visões de mundo muitíssimo diferentes. Na minha pesquisa atual de pós-doc., mapeio literatura lésbica em termos de autoria e representação. Uma grande produção poética tem se destacado e, nela, temas, imagens e metáforas que eu ainda não havia encontrado em outras leituras. É evidente que essas vozes importam política e culturalmente, mas também estética e teoricamente.

PD: Você foi agraciada com dois Jabutis e com um Açorianos pelos seus contos. Você também publicou poesia. Há um romance a caminho?

NBP: Publiquei poesia, sim, mas não sou muito fã do meu livro (risos). Gosto muito do título Coração a corda, mas acho que falta um trabalho ali. Este ano publico mais uma coletânea de poesia com o título de Pé atrás, que explica muito da minha relação com meus poemas. Publico com dois amigos, os poetas Marco

\footnotetext{
${ }^{3}$ https://revistacult.uol.com.br/home/quem-e-e-sobre-o-que-escreve-o-autor-brasileiro/.
} 
de Menezes e André Ricardo Aguar. Criamos um selo e estamos fazendo a coisa toda de modo independente, o que me deixa bem feliz. Explorar os diversos caminhos de produção de um livro é das coisas que gosto de aprender. Sobre um romance, sim, temos um a caminho, se chama Controle, já com editora, mas não posso dar muitos detalhes. Apenas digo que é um romance de formação e que a personagem principal é uma garota que tem epilepsia. Além disso, estou escrevendo outro romance agora, este anda exigindo muita pesquisa. Tenho me divertido bastante!

PD: Podemos então esperar outro Jabuti no futuro? Mas na categoria romance?

NBP: (risos nervosos) A gente sempre espera algum reconhecimento. Não precisa ser na forma de um prêmio, não posso esperar que a cada livro eu ganhe o prêmio dito de mais prestígio na literatura brasileira (mais risos nervosos), além do mais, tenho acompanhado com muita alegria a produção literária atual e muitas coisas têm me agradado. Por enquanto, me preocuparei em desenvolver bem minhas personagens e minhas histórias. A recepção eu deixo pro público, pra crítica e seja o que as deusas quiserem.

PD: Há uma pergunta que não fiz (ou assunto no qual não toquei) que você gostaria que tivesse sido feita?

NBP: Creio que não. Gostei das perguntas e acho que gostei das respostas também. Tenho uma pergunta pra ti: por que esta entrevista? O que te motivou?

PD: Por sermos tão diferentes à primeira vista (e impressão) pensei que, se você concordasse, seria uma via interessante de diálogo. As diferenças, algumas tão estigmatizadas, são construídas e ensinadas como tal num processo de (de)construção de identidades: masculinas, femininas, hétero, homo, negras, brancas, mestiças, gaúchas, fluminenses. A lista é longa. Como você mesma disse, "apresentar é sempre dar margem a uma perspectiva interessante de nós" e, quando você fechou os olhos com as mãos (gesto emblemático), não pude também deixar de experimentar um sentimento amargo em relação à (falta de) visibilidade das mulheres, e isso me motivou a fazer esta entrevista. E aqui ocorreu o dilema já que havia e há o risco de interpretar-se como pedantismo eu 
achar que poderia proporcionar alguma visibilidade à ganhadora do Prêmio Jabuti. Isso também influenciou muito na escolha das perguntas. Resolvi correr o risco.

NBP: Fico sempre muito contente quando encontro essas afinidades que, para além do campo teórico, se desenvolvem em afetos, identificações e modos mais relevantes de ocupação dos espaços, sejam esses espaços eventos, revistas, instituições, etc. Portanto, aceitar o convite para esta conversa também teve o intuito de celebrar este encontro. Quando estabelecemos tensões no campo literário, essas têm o objetivo de criar certa equanimidade de produções e de produtores, certa igualdade, mas acaba evidenciando, paralelamente, certas diferenças, o que é excelente! A lista é longa mesmo, nos dois extremos, e não é maravilhoso que justamente os pontos em comum possam gerar diálogos tão profícuos? A visibilidade passa por aqui também. 